\section{The diagnosis and management of food allergy}

Sir,

In his article on food allergy Dr Cant discusses abnormal psychological reactions of some parents of children with food allergy but fails to mention similar problems in children who have grown out of the disorder. ${ }^{1}$ My 6 year old son outgrew his cow's milk allergy two years ago and now eats a normal diet. Despite all our efforts to the contrary, however, he still eats his breakfast cereal without milk and his puddings without custard, and it has taken two years of intensive retraining to persuade him to eat ice cream. While this is not a great problem, I feel that other children will have more serious long term psychological effects from restriction diets for food allergy and this aspect has not been widely documented in the past.

\section{Reference \\ 1 Cant A. The diagnosis and management of food allergy. Arch Dis Child 1986;61:730-1.}

R J WELCH Newcastle General Hospital, Newcastle upon Tyne

\section{Pulse oximetry in neonatal care}

\section{Sir,}

The pulse oximeter, a fast non-invasive method of continuous arterial oxygen saturation monitoring, is beginning to be used in neonatal units as a prompt warning of hypoxaemia in the unstable baby. The device measures the absorption of selected wavelengths of light passed through a sample of living tissue from which the quantity of oxygenated and reduced haemoglobin can be calculated. The neonatal probe is designed to be wrapped around a hand or a foot. It is unheated and not adherent to the skin. We report an added use for this device.

A $620 \mathrm{~g}, 25$ week old baby born in this hospital had moist friable skin. Even foam backed electrocardiogram electrodes caused trauma to the superficial skin layers, resulting in risks of introduction of sepsis and increased fluid losses. We anticipated a conventional heated transcutaneous oxygen sensor would do the same. We therefore monitored this ventilated baby entirely using the pulse oximeter (Ohmeda Biox 3700), placed around an upper arm and occluded from ambient light. This allows digital read out of heart rate and oxygen saturation, a graphic display of the pulse, and high and low alarms for all readings. This was used successfully for two weeks, producing no skin trauma and no complications and a reduced need for handling the infant. This device may reduce handling and skin trauma in the monitoring of heart rate and arterial oxygen saturation in immature infants with friable skin, who require neonatal intensive care. Direct arterial oxygen partial pressure monitoring, through an indwelling line, is also required to detect hyperoxaemia, as on two occasions this baby had an oxygen tension of 15 kilopascals when the pulse oximeter reading was $93 \%$.

M E I Morgan and G M Durbin Birmingham Maternity Hospital, Queen Elizabeth Medical Centre, Birmingham B15 $2 T G$ 